\section{Customer experience of product quality: a new metric}

How a product looks, feels, sounds,
tastes, or smells

DURABILITY:
Measure of the product's useful life

\section{EASE OF USE:}

Ease of understandability and comfort

\section{FEATURES:}

Secondary aspects of performance,

s and whistles" of products quality means doing it right is certainly what customers hope has happened in the production of the durable products they purchase, from cars to smartphones. But what do we really mean by product quality and how should it be measured? Professor Marcel Das Guru from the University developed and validated a new multi-dimensional product quality scale - the Customer Experienced Product Quality (CEPQ) use product quality to drive business performance.
Henry Ford famously said that when no one is looking. That Paulssen and Dr Ramesh Rosha of Geneva in Switzerland have metric - to help manufacturers \section{roduct quality has long been
recognised as a key factor in
driving business performance} driving business performance
and achieving competitive advantage, example, while an engineer might conforms to certain design standards and specifications, a customer might perceive quality according to whether the door closes with the right kind of quality according to the size of the engine.

Customers' perceptions count. Their experience of product quality - their judgement of the overall excellence or superiority of a particular product relative to alternatives - influences their future purchasing behaviour, their willingness to pay as well as the degre to which they would recommend a Customer experience of quality is different from custo or qualisy is it is more complex than simply giving a four-star rating on an online into customer behaviour, we find that customers experience product

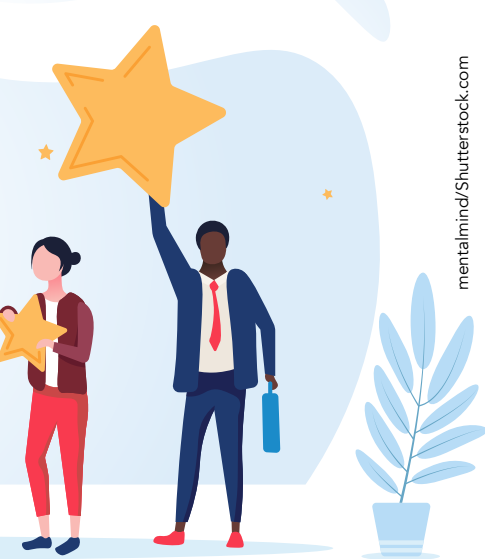
sut what we mean by quality can be judge qual ity according to whether a click, and yet another might judge shopping portal. Digging deeper quality in a multi-dimensional way. It involves consideration of a product's performance and primary operating characteristics, as well as other base product-for example, additio features, its durability or its aesthetics.

It is therefore vitally important for manufacturers of durable goods to know how different dimensions of product quality are experienced by their customers. While there are recognised research instruments such as SERVQUAL and SERVPERF, which measure customer service quality, metrics for assessing exactly how customers experience product quality have been lacking.

New research to develop such a metric is therefore timely. Professor Marcel Paulssen and Dr Ramesh Roshan Das Econ, from the Geneva School of University of Genava in Switzet have developed a multi-dimensional Product Quality' (CEPQ) scale, which identifies and measures how customers experience and respond to the quality of products. They have tested the validity and reliability of the CEPQ metric across diverse product categories

\section{THE STUDY}

Professor Paulssen and Dr Das Guru began with exploratory research into the factors that influence customers' quality experience for durable products. Online surveys with customers were carried out four product and the Unired States in four product categories, which covered: cars, smartphones scale called the 'Customer Experienced

\section{PERFORMANCE:}

characteristics

\section{RELIABILITY:}

The probability of a product

specified period

\section{SERVICEABILITY:}

The speed, courtesy, competence, and

ssociated with the product

\section{MATERIAL:}

The standard and robustness of materials \section{Table 1. Dimensions of Customer Experienced Product Quality (CEPQ) illustrated with verbatim responses from the exploratory study} ro to expect seven quality dimensions.

These dimensions were:

pliablity, durability

ease of use, aesthetics

and senviceability These

were confirmed in the

exploratory research across categories. In addition, the surveys identified the importance of an eighth factor: the quality of materials used in the prod manufacture. The eight identified dimensions of quality were validated in a pre-test in two product categories with US customers.

The main study covered four product categories - cars, dishwashers, Wascont an from the United States. Respondents It should beat out most if not all other products of its type." "A used in everyday life without worrying about it breaking down." "A "A service must be of high quality." quality dimension across all quality.

\section{ANALYSIS OF DATA}

Analysis of the data from the main study produced significant insights. First, the eight identified product quality dimensions could be validated in all fo product categories of the main study.

Second, previous research considered product quality as a mere antecedent of all product categories.
The product's primary operating

A preliminary literature review had
"To me, a high-quality product has to have the look and feel of high craftsmanship." "A high-quality car needs to look very sleek and attractive from outside and should "A product with perfect quality will work flawlessly forever without any

(hitis is durable but low quality is not durable."

"A high-quality product should be comfortable to use and should not need too

"The easier to drive in any conditions the more high quality the product it is." Its camera, music player, support for various web browser, its RAM and high product for me." "A high quality product is defined by its performance compared to its competitors.

"Ahigh-quality smartphone would be one that provides very clear and reliable

"Product quality to me means a product that is something dependable and can

"A low quality product gives various issues every now and then but a high quality "f the product breaks down, it can be repaired easily without much hassle."

"A high-quality product would include higher-end fabrics, finishes, and materials. "A plece of high quality "furniture, for example, would be made of all real wood." "The material used to make the running shoe must be of the first-class because The most significant product to pay premium (WTPP) or products was performance. has a strong, direct effect on both WTPP and RI over and for a minimum of 6 months and were above customer satisfaction. Customer asked about their product experience on satisfaction only partially mediates the eight identified dimensions of product the effect of CEPQ on relationship outcomes. Especially for WTPP, the direct effect of CEPQ accounts for categories. For Rl, the relative impact of weative \%o\% of the tota fect tis part in $40 \%$ of the total effect. It is particularly CEPQ is stronger than the toct of satisfaction for both Rl and WTPP "ack up camera, Bluetooth capability. Any kind of fancy wheels or sunroof." "A high-quality car should need minimum servicing and when it does need it, around $50 \%$ of the total effect across 


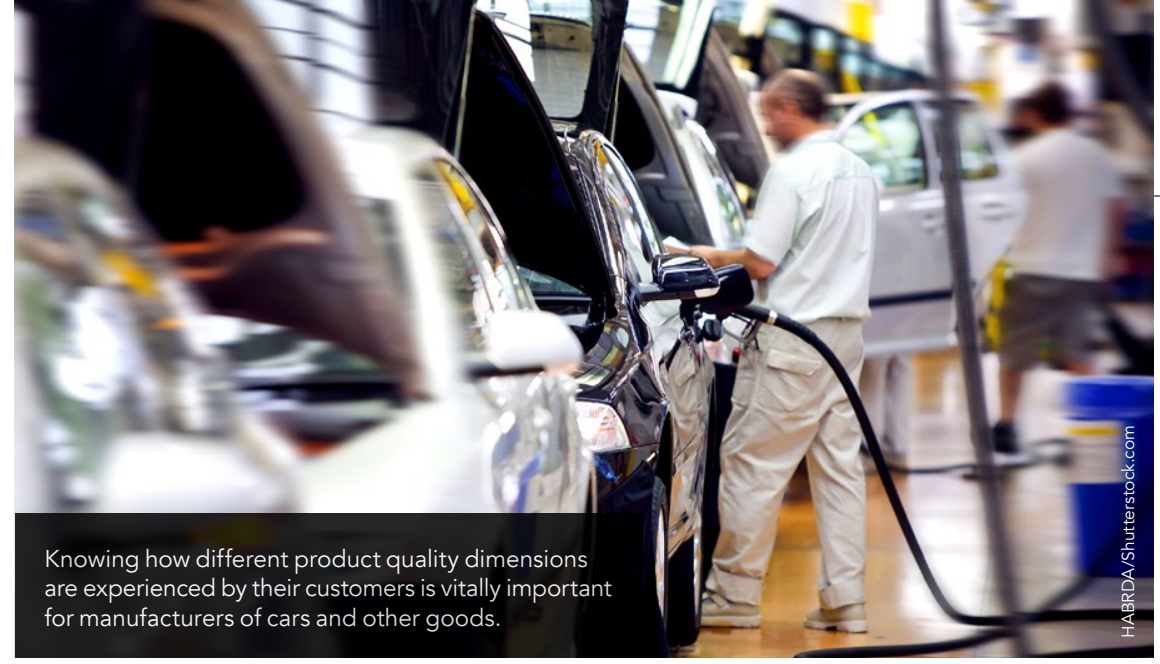

Moderators for the relevance of CEPQ were also identified. The degree to which a consumer focuses on buying high-quality products, their 'quality consciousness', as well as their leve of expertise moderated the impact of CEPQ on outcomes (Rl and WTPP). For high-quality conscious customers and experts, the disect effects of CEPQ on and WT are stronger than the effects cases In all four product categories, the direct effect of satisfaction on WTPP is not significant for high-quality consciour customers. Thus, for some substantial and relevant customer groups, i.e. experts and quality-conscious customers, satisfaction is simply not the most relevant metric, bu instead CEPQ is.

\section{A NEW METRIC}

Importantly, the multi-dimensional

product quality scale with its eight quality dimensions developed by Professor Paulssen and Dr Das Guru has by now been validated across a diverse set of product categories ranging from lawn
mowers to televisions.

Dr Paulssen and Dr Das Guru have found that their CEPQ metric is more sophisticated in its insights when

compared to alternative quality metrics, platforms. By drilling down and revealing how the quality dimensions relate to each other, the CEPQ metric provides a more comprehensive and diagnostic insight into how product quality is experienced in a category

The most significant product quality dimension across all products was performance. However, for all other dimensions, results differed depending on the product. For tablet computers, the additional dimensions were serviceability,

ease of use, and features; for dishwass
they were material, features, and product quality in specific product customer satisfaction. In addition, they new product development. It can also enable operations managers and produ quality dimensions and thus allocact resources more effectively for improving the quality of their products.

In addition, the CEPQ metric can be applied to different market segments within a product category, for exampls to help companies develop products or target messages at specific market segments. Professor Paulssen and Dr Das Guru explain: "This segment-specific, dimensional significance is crucial for product managers when targeting and positioning existing and new products by allowing them to priorise which product aspects to focus on in research development for new products."

\section{A KEY MEASURE FOR BUSINESS}

While customer satisfaction has

traditionally been regarded by companies

customer evaluation of a product's

performance across eight quality

dimensions into an overall quality

his alone is not a sufficient predictor of

It is vitally important for manufacturers

of durable goods to know how different dimensions of product quality are experienced by their customers.

judgement. Based on actual experience, future purchase behaviour. Rather than the $C E P Q$ metric helps companies understand how customers defin categories.

Professor Paulssen and Dr Das Guru's research shows that CEPQ is a better than other established metrics such as suggest that measuring and tracking CEPQ on a regular basis can help companies "to decode exactly how their customers experience product quality and can pinpoint strengths and weaknesses of a company's product portfolio on a quality dimension level". The insights generated can help to both improve production processes and inform

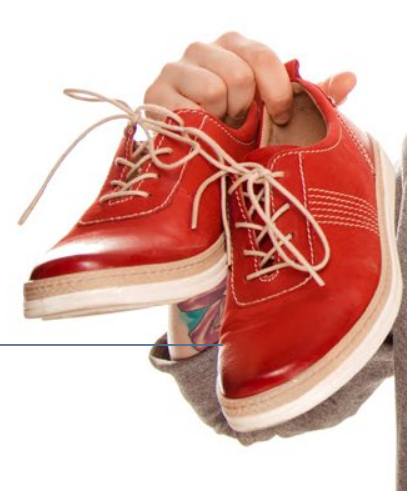

being regarded as an antecedent to customer satisfaction, Professor Paulssen and Dr Das Guru's study shows that (CEPO) drives key ced Product Quality (CEPQ) dives key customer behaviours It follows that the CEPO metric they have developed should become both a key measure of business performance and a subject for further research.

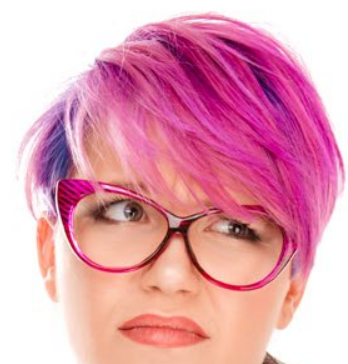
.

\section{Behind the Research}

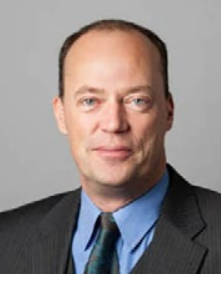

Prof Marcel

Paulssen

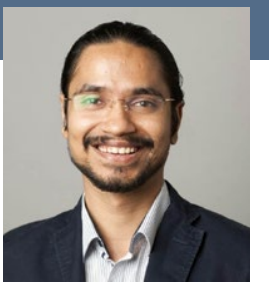

Dr Ramesh

Roshan Das Guru

:marcel.paulssen@unige.ch T.+41 223798940 W: https.//www.unige.ch/gsem/en/research/taculty/all/marcel-paulssen $/$ / -paulssen-8198688

Research Objectives

Professor Marcel Paulssen and Dr Ramesh Roshan Das Guru have developed a multi-dimensional Customer Experienced Product Quality (CEPQ) scale to help boost business performance through assessment of product quality.

\section{Detail}

\section{Address}

Marcel Paulssen
Professor of Marketing

Director of the Institute of Management

Geneva School of Economics \& Management (GSEM)

University of Geneva, Uni-Mai

40, Bd du Pont d'Arve 1205 Geneva, Switzerland

Bio

\section{References}

Paulssen, M. and Das Guru, R. (2020). Customers'

experienced product quality: scale development and
validation. European Journal of Marketing, 54(4), 645-670. validation. European Journal of Marketing, 54(4), 645-670.
Available at: https://doi.org/10.1108/EJM-03-2018-0156

UNIVERSITÉ
DE GENĖVE GENEVA SCHOOL OF ECONOMICS AND MANAGEMENT

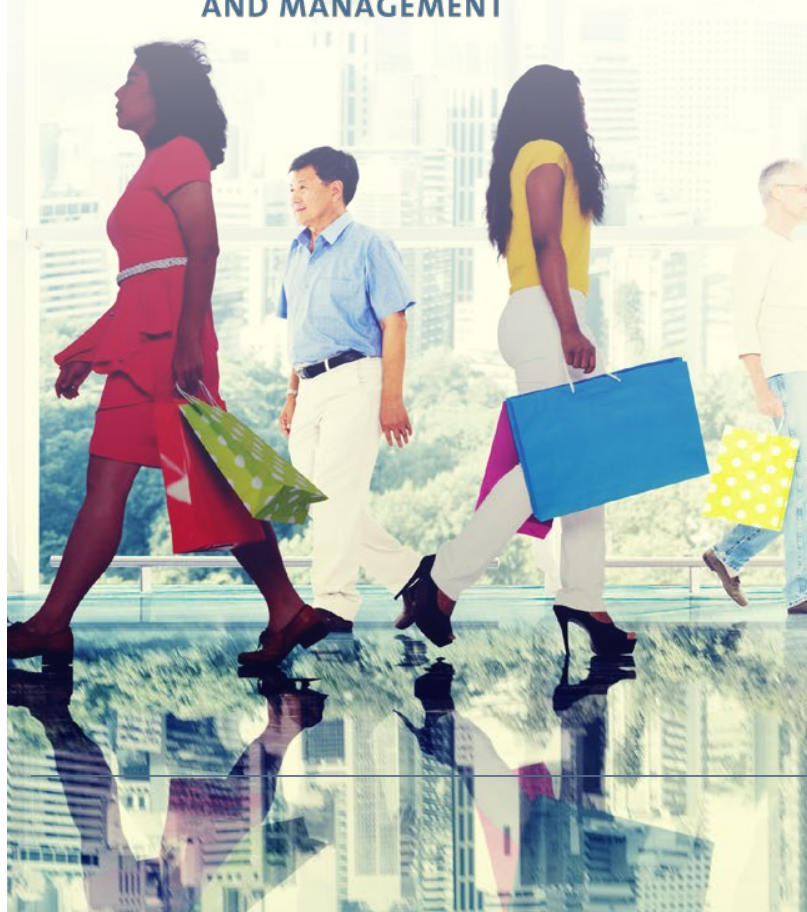
Guru is a Rese of Management. Ramesh Roshan Das Economics and Management In their current research projects, both work on product defects and product quality perceptions.

\section{Personal Response}

What was the most surprising insight into customer experienced product quality gained from your research?

II It was quite surprising to observe that despite theoretical conceptualisation of product quality insisted on its multidimensional nature, no scale existed to capture scale being so significant and around for decades.
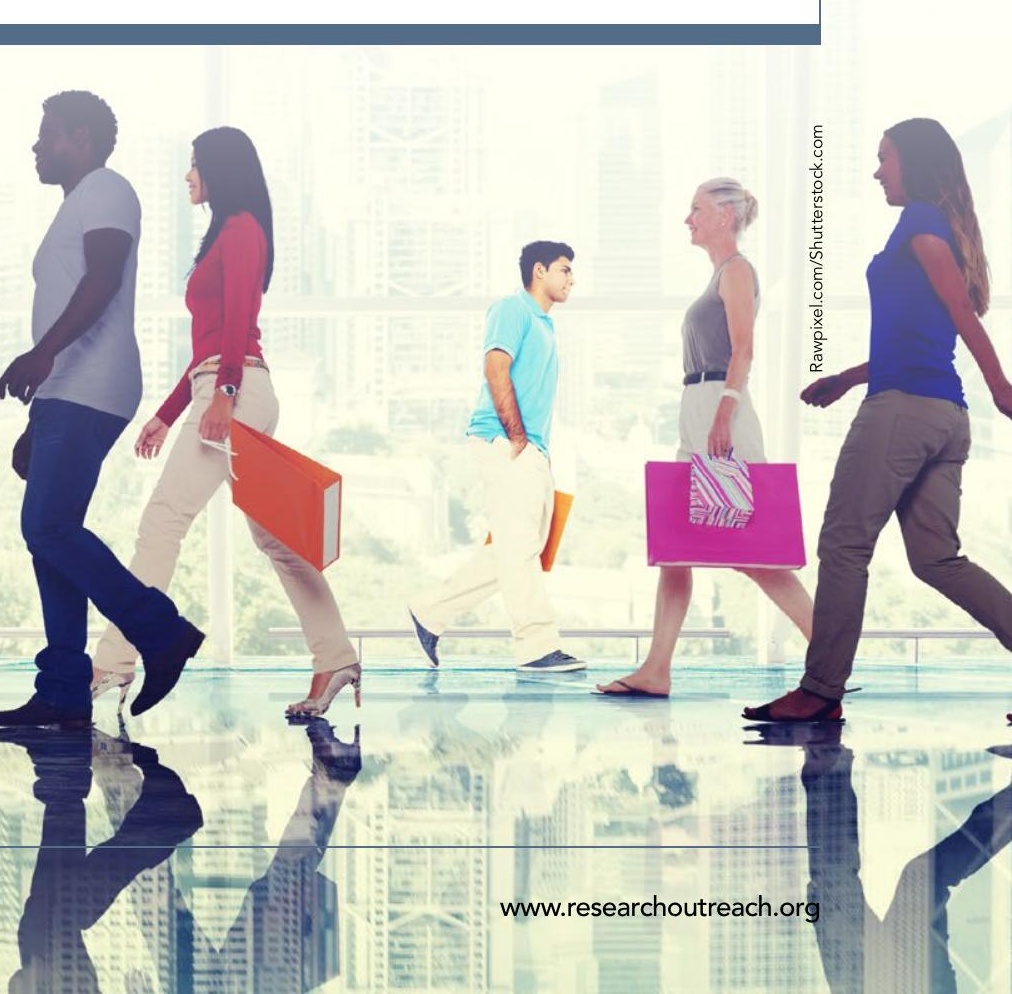